\title{
Geotechnical Behaviour of Reinforced Soft Clay by Marble Dust as a Waste Material
}

\author{
M. N. Elsiragy \\ Assistant Professor of Geotechnical Engineering at Construction \& Building Department Faculty of Engineering, \\ October 6 University, Giza, Egypt.
}

\begin{abstract}
-
Civil engineers around the world are in search of new alternative resources which are required both for cost-effective solutions for ground improvement and conservation of scarce natural resources. The various methods of ground improvement currently in use include lime columns, stone columns, use of chemical stabilizers, and various kinds of inclusions like metal strips, mats, fibres, geosynthetics, etc. The cost of these virgin materials as well as the processes involved is usually high and as such, they are yet to be commonly used in developing foundation performances. This paper illustrates the application of using marble dust stabilization in improving the soft clay soil. Various tests with different marble dust contents were performed to study the effect of using material as a stabilizing technique on main geotechnical soft clay properties. A series of laboratory tests like plasticity and consolidation at a different percentage of marble dust has been done. These experiments showed that the addition of marble dust resulting in composites hardens material which reduced the plasticity and compressibility parameters of the reinforced soft clay. The induction of reinforced composite material successfully decreases and adsorbs the excess water inside the soft clay thus, modifying the soft clay plasticity and significantly increase the soft clay stiffness and decrease the settlement. The used marble dust reducing the volumetric shrinkage and produced isotropic compressible ductile material with less settlement and higher shear strength. This adopted method will be applied to unravel the geotechnical stabilization issues, for instance, road embankments modification and foundation use.
\end{abstract}

Keywords: Soft Clay, marble dust, consolidation, Shear strength, Isotropic material.

\section{INTRODUCTION}

Soft clays are characterized by containing high water content, low bearing capability, high sponginess, and also the plasticity index of the soft clay is incredibly low. The reduction in strength and stiffness of soft clays leads to bearing failure and excessive settlement, resulting in severe damage to buildings and foundations. In Egypt, soft clays are cosmopolitan within the Central and Northern elements of the river Delta, wherever they vary in thickness from less than one meter to quite $15 \mathrm{~m}$. Soft clays became issues of major importance to geotechnical engineers. The capability to style associate hill economically on a clay foundation and to predict its behavior are so of nice interest to the profession. Cases show that many problems occur due to the compression of the clay layer causing foundation collapse. That is why many researchers employ soil stabilization techniques to improve the geotechnical characteristics of the clay soil to maintain roads, prevent structures from collapsing, control foundation settlement, and evade any associated failure. For example, cement was first used as a stabilizing agent at the beginning of the 20th century.

It was mixed with the soils to form road material and was used in a wide range of applications all over the world. Since then, many other material types, such as lime [1], fly ash [2] organic marble contents [3] and their mixtures [4] have been used as stabilizing agents. Ref [5] studied the engineering properties of clay materials reinforced with randomly oriented fibers. Also, several researchers [6], [7] and [8] investigated aqueous marble content applications while others [9], [10], and [11].

Provided useful data on the marble content-soil interactions that determine the effectiveness of marble content solution in various applications. Whereas marble dust can be widely adopted to improve the geotechnical properties of soils as a waste available cheap martial and environmentally acceptable. Ref [12] indicates that the quantity of marble waste generated by the extraction process may be up to $80 \%$ of the whole volume of stone extracted. Ref [13] evaluated the geotechnical properties of red tropical soils treated with marble mud. It is reportable that physical property is reduced and compressive strength inflated with the addition of marble mud. Ref [14] detected that the optimum wetness content (OMC) of the soil is reduced due to the lime effect. Ref [15] suggested that most dry density (MDD) of soil is ablated with sedimentary rock mud content recognition to ion exchange reaction that reduces the burden volume quantitative relation.

The CBR worth of existing soil is inflated with sedimentary rock content thanks to ion exchange, flocculation agglomeration reaction, and building material gel formation. Ref [16] performed a test experiment wherever completely at different percentages of marble mud which were supplemental $(3,6,9,12$, and 15\%) at completely different natural process periods of 3,7 , and 14 days to the soil sample to see the essential properties of treated soil like Atterberg limits, compaction characteristics, and strength characteristics. The CBR value of the untreated and treated soil at zero and stabilized with marble mud was recorded to be 5.19 and $8.83 \%$, severally. Reff [17] prompt that the swelling potential of clayey soil may be improved 
with the addition of marble mud. Marble mud stable clay soil gain additional than forty-eighth compressive strength from the untreated clay soil.

\section{TESTING MATERIALS AND EXPERIMENTAL APPROACHES}

Tests Soil

The soft clay samples used in the study were fabricated for kaolinite which the Supplier from Cairo, Maadi, Egypt. Obtaining undisturbed soft clay samples from the site is too difficult so, the clay has been prepared in the laboratory using kaolin according to [18]. The procedures of making ready of clay within the laboratory were represented as shown within the following. porcelain clay-based mostly artificial soils are significantly well-liked for laboratory work and have been widely used in basic studies of soil behavior and physical model tests. The properties of pure porcelain clay are somewhat typical of natural clay soils. The mineralogical and chemical properties of the tested mineral printed by the manufacturer were conferred in Tables (1) and (2).

TABLE I

MINERALOGICAL COMPOSITION OF THE KAOLINITE USED IN THE STUDY

\begin{tabular}{|c|c|}
\hline Type of Mineral & Volumetric Content (\%) \\
\hline Clay Mineral & 90. \\
\hline Sodium Feldspar & 2.1 \\
\hline Potassium Feldspar & 2.50 \\
\hline Free Quartz & 5.12 \\
\hline
\end{tabular}

TABLE II

CHEMICAL COMPOSITION OF THE KAOLINITE USED IN THE STUDY

\begin{tabular}{|c|c|}
\hline Element & Result (\%) \\
\hline Silicon dioxide $\left(\mathrm{SiO}_{2}\right)$ & 52 max \\
\hline Aluminum oxide $\left(\mathrm{AL}_{2} \mathrm{O}_{3}\right)$ & 34 min \\
\hline Iron oxide $\left(\mathrm{Fe}_{2} \mathrm{O}_{3}\right)$ & 1.2 \\
\hline Titanium dioxide $\left(\mathrm{TiO}_{2}\right)$ & 1.50 \\
\hline Calcium oxide $(\mathrm{CaO})$ & 0.25 \\
\hline Magnesium oxide $(\mathrm{MgO})$ & 0.10 \\
\hline Sodium oxide $(\mathrm{Na} 2 \mathrm{O})$ & 0.13 \\
\hline Potassium oxide $\left(\mathrm{K}_{2} \mathrm{O}\right)$ & 0.04 \\
\hline Chlorine $(\mathrm{Cl})$ & $<0.05$ \\
\hline Loss on ignition $\left(105^{\circ} \mathrm{C}-1000^{\circ} \mathrm{C}\right)$ & $11-12$ \\
\hline
\end{tabular}

Ref [19] evaluated that the high-plastic soil may be improved by adding ceramic mud at a completely different proportion. As ceramic mud cohesion lessens, the cohesion of the treated soil is reduced and the angle of internal friction improved. The unconfined compressive strength of soil increased with the addition of marble to the soil. Li et al., 2019 reportable that marble will be accustomed to replace either cement or paste. The strength and microstructure of concrete can be improved if marble mud is employed as a paste in cement. According to technical data for stabilization of soil, this study endeavors to apply the technique of using a waste available material like marble dust to show their effect on the engineering characteristics of soft clay.

The main aim of this idea analysis is to exploit compounds to enhance the geotechnical properties of soft clay soil supported by the modification of clay strength. This system is often additionally effectively accustomed improve the soft clay characteristics for installations of road embankments and stabilizing the loaded clay slopes.

\section{PREPARATION OF SOFt Clay Slurry In THE LABORATORY}

The tests were performed on samples to determine the properties of the prepared soft clay and to ensure compliance of the clay prepared in the laboratory with the properties of the natural soft clay. The following tests were conducted on the clay which is, Specific gravity, hydrometer test, Atterberg limits tests, and direct shear box. The main obtained geotechnical properties are shown in Table 3 .

TABLE III

KAOLIN PROPERTIES USED AS A SOFT CLAY

\begin{tabular}{|c|c|}
\hline Kaolin Index Properties & Soft Clay \\
\hline Specific Gravity (Gs) & 2.72 \\
\hline Water Content & $34 \%$ \\
\hline Cohesion (Cu) $\mathrm{kN} / \mathrm{m}^{2}$ & 14 \\
\hline Angle of Internal Friction ( $\phi)$ & $28.70 \%$ \\
\hline Liquid limit (L.L) & $15 \%$ \\
\hline Plastic limit (P.L) & $13.7 \%$ \\
\hline Plasticity index (Ip) & 16.9 \\
\hline Maximum dry density $\mathrm{kN} / \mathrm{m}^{3}$ & 11.23 \\
\hline Optimum moisture content $\%$ & $1 \mathrm{C}$ \\
\hline
\end{tabular}

The used marble dust MD was collected from Shaq ElThoaban industrial area, Egypt. In geological terms, marble is basically a metamorphic rock that is formed when limestone undergoes very high thermal and pressure energy, and this process is known as metamorphosis. When marble quarries and stones are cut as blocks, $25-30 \%$ of the total marble becomes unusable waste in the form of marble powder. Marble has very high lime $(\mathrm{CaO})$ content, which acts as the main factor for soil stabilization.

The used marble mud MD was collected from Shaq El-Thoaban industrial space, Egypt. In earth science terms, marble is essentially a rock that is created once stone undergoes terribly high thermal and pressure energy, and this method is understood as metamorphosis. Once marble quarries and stones are cut as blocks, 25-30\% of the entire marble becomes unusable waste within the type of marble powder. Marble has terribly high lime $(\mathrm{CaO})$ content that acts because the main issue for soil stabilization.

Quick lime $(\mathrm{CaO})$ is the main constituent of marble dust and it is the main component that helps in the stabilization of the soil. It is seen that the marble dirt incorporates the most parts of the natural rock and at intervals the averages used for cement trade wherever $\mathrm{CaO}$ reaches $55 \%$, $\mathrm{SO} 3-<1.0 \%$, alkalis $<1.0 \% \mathrm{MgO}=0.25 \%$ and $\mathrm{Cl}-=0.07 \%$ The mineralogical composition of adopted 
marble dust is $45 \%$ calcite, $36 \%$ dol0omite, $13 \%$ Quartz, and $8 \%$ illite.

\section{Preparation of The Marble Dust - Clay COMPOSITES}

To prepare the stabilized kaolinite/clay powder with marble dust, physical mixing was adopted. According to the methods of statement and specification recommendation by AASHTO M 145. The tested samples of the soils were ovendried at $120^{\circ} \mathrm{C}$, next graded, pulverized, and sieved through a No.14 $(1.2 \mathrm{~mm})$ strainer. According to the arid weight of the soil, the proper amount of marble dust was added. A kitchen stand blender was used to merge the marble dust with the kaolinite clay with a total mixing time of 5 to 10 minutes.

\section{TESTING PROCEDURES}

The amounts of marble dust added to the soft clay soil samples, as a percentage of the dry soil mass, were $(0,5,10$, and 15 mass \%). All tested samples were remolded at their optimum moisture contents (OMCs) and maximum dry densities (MDDs) with the proctor test related to the ASTM (D-1557) specification of the compaction test. The compaction curves for mixtures of different plasticity values prepared with different percentages of marble dust are shown in Figure 1. It was noticed that increasing the marble dust percentages extraordinarily increased the dry density even as the optimum moisture content was reduced. This increase in the maximum dry density is due to the formation of soft clay dust interaction. Besides, the volume of the treated sample decreased and its total weight increased. Decreasing the optimal water content was back to the absorption of the increased water by the marble dust through the clay samples in the initial chemical reaction.

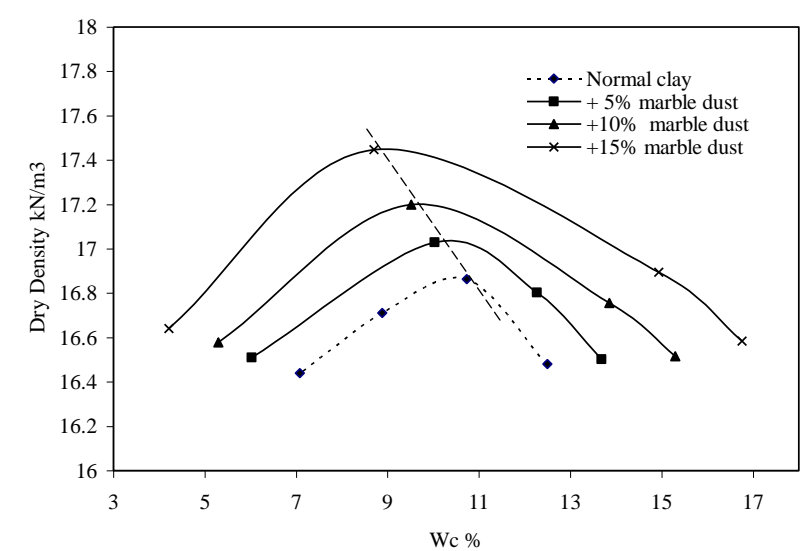

Figure 1. Compaction curves for stabilized soft clay samples at different marble content

After the mixing process, the stabilized clay sample by marble dust was compacted to the given density and installed in a PVC cylinder form (76 $\mathrm{mm}$ in height and $38 \mathrm{~mm}$ in diameter), and rings, $(75 \mathrm{~mm})$ in diameter and $(19 \mathrm{~mm})$ in height, to be tested in unconfined compression test and odometer respectively. A series of tests was conducted to look at the result of the compound of soil marble dust on the mechanical and compressibility characteristics of tested clay samples. All the performed tests were done per (ASTM) specifications, at each totally different compound content and also the relevant (MDDs) amid corresponding (OMCs). On the other hand, to determine the unconfined compression strength parameters of unstabilized and stabilized samples, a series of unconfined compression tests were carried out according to (ASTM D2166-65) at the rate of $1.2 \mathrm{~mm} / \mathrm{min}$. All samples were tested after 14 days of curing time.

\section{VOLUMETRIC SHRINKAGE}

The stabilized samples by such marble dust were measured to get the volumetric shrinkage characteristics with proctor molds as stated by (Puppala and Musenda 2000). In this technique, oven-dried, reconstituted soil was mixed with water at the liquid limit state to make suspension at completely different chemical compound contents. The mix was then poured into the mold and gently tamped. After, the specimen within the mold was placed in the oven at $80^{\circ} \mathrm{C}$ for forty-eight hours. Throughout this era, the mold was turned the wrong way up and revolved often to permit uniform shrinking and drying of the specimen and to avoid or minimize cracks. Thereafter, the diameters and heights were measured at 3 completely different locations, and therefore the averages were noted to calculate the meter shrinkage strain values.

The stabilized samples by such marble dust were measured to get the volumetric shrinkage characteristics with proctor molds as stated by (Puppala and Musenda 2000). In this technique, oven-dried reconstituted soil was mixed with water at the liquid limit state to make suspension at completely different chemical compound contents. The mix was then poured into the mold and gently tamped. After, the specimen within the mold was placed in the oven at $80^{\circ} \mathrm{C}$ for forty-eight hours. Throughout this era, the mold was turned the wrong way up and revolved often to permit uniform shrinking and drying of the specimen and to avoid or minimize cracks. Thereafter, the diameters and heights were measured at 3 completely different locations, and therefore the averages were noted to calculate the meter shrinkage strain values.

\section{RESULTS AND DISCUSSIONS}

\section{A. Clay Marble Dust Compaction Characteristics}

The addition of marble dust to reinforce soft clay soil for constructing a new material composite through the clay voids is considered as a new area of stabilization. In this research, it is adopted to improve and modify the behavior of the tested soft clay. Figure 1 presents the compaction curves for a reinforced sample at different marble content. It can be seen that the existence of such marble dust can significantly improve the dry density of the natural soft clay without additives. It also modified the fabric or clay microstructure that showed the orientation and arrangement of the soft clay 
skeleton. It has been considerably found that the mixing of marble dust to soft clay modifies the microstructures fabrics and clay mineralogy due to the interaction between marble dust and soft clay. As shown in Figure 1 this but also increases the field density due to the satisfying of voids, where the void spacing reduced within the clay matrix. The marble dust was distributed within the clay matrix in aggregates of various sizes; this indicated homogeneity distribution of compound inside the clay sample. The marble mud stabilization inflated Infobahn's electrical attraction between adjacent grain particles.

It conjointly improved the grain surface of the tested clay against water by constructing the new composite material that fills the voids. Once the marble mud is mixed with clay samples, the surplus water is often effectively absorbed as even by the reduction of the optimum wetness contents (OMC). Hussain et al. 2006 and Kiliarisand and Papaspyrides 2010). This additionally confirmed the reduction within the optimum wetness content (OMC) that was noticed within the compaction curves and a reason given for the decrease in (OMC) values as shown in Figure 1.

The voids which are decreased and filled with marble dust amplify the adhesion and improving the clay character. That is backed to the interaction between the percent of lime $(\mathrm{CaO})$ content within the composition of marble dust of the. That confirms the beneficial reduction on the excess water and produced cemented material due to hydration as a pozzolanic reaction. Due to the addition of marble dust with soft clay in the presence of water, a put of reaction is considered that results in the dissociation of lime $(\mathrm{CaO})$, consist of calcium silicate hydrate gel(CSH), calcium aluminate hydrate gel $(\mathrm{CAH})$.that fill the voids and lead to increase of dry density with the increase of marble content as confirmed by (Al- Wardani 2011).

\section{EFFECT OF MARBLE DUST ON GEOTECHNICAL CLAY PROPERTIES}

\section{Effect of Marble Dust on Soft Clay Plasticity}

In this division of investigation, the effect of the alteration of stabilized soft clay by marble dust on the engineering properties of soft clay was studied. It has been found that mixing the adopted dust to soft clay can notably modify the consistency behavior of the treated samples due to the produced composite reinforced material. The induced materials within the soft clay Skelton appreciably modified and reduced both the liquid and plastic limit.

It is noticed that, as the marble content increases, the plasticity of the composite material extremely decreased. Thus, the talent of the new composite material to take up the excess water is obtained; therefore, the plasticity index is gradually decreased. The marble dust stabilization increased the net electrical hold amongst the closest soft clay particles. It also improved the grain surface of the tested soft clay against water by constructing a hardened material with lesser water contents.
MARBLE DUST CONTENTS AND PLASTICITY OF STABILIZED SOFT CLAY AT DIFFERENT

\begin{tabular}{|c|c|c|c|}
\hline $\begin{array}{c}\text { Marble } \\
\text { content } \%\end{array}$ & $\begin{array}{c}\text { Liquid limit } \\
\text { LL\% }\end{array}$ & $\begin{array}{c}\text { Plastic } \\
\text { limit PL\% }\end{array}$ & $\begin{array}{c}\text { Plasticity } \\
\text { index PI\% }\end{array}$ \\
\hline 0 & $28.70 \%$ & 15 & 13.7 \\
\hline 5 & 26 & 12 & 14 \\
\hline 10 & 19 & 10 & 9 \\
\hline 15 & 13 & 5 & 7 \\
\hline
\end{tabular}

\section{EFFect of MARble Dust on The Soft Clay COMPRESSIBILITY}

For the aim of comparison and mention of the effect of marble dust on the soft clay, compression behaviors can chiefly be given in terms of void ratio relation instead of vertical strain. The softness results of the soft clay stabilized with marble dust are shown in Figs 2 (a to e).

Figure $2 \mathrm{a}$ shows thee-logo compression curves at different marble contents. It is noticed that, the slope of the virgin curve of consolidation (post-yield) line altered while the rate of stabilized soft clay stiffness enhanced, whereby (0\%) marble content gives a steeper post-yield incline, followed by $(5 \%, 10 \%$, and $15 \%)$ in that order. It also obtained higher effective yield stress. This shows that when marble content is added to soft clay, the specimen is appeared stiffer due to the construction of the hardened material (CHS) of pozzolanic reaction inside the soft clay voids. The compression (Cc) and swelling index or recompression index $(\mathrm{Cr})$ through unloading were recorded at different marble content contents. It can be seen that the marble content stabilization clearly reduced the compression index values (Figure $2 b$ ). The normal specimens vary from a void ratio of approximately (1.235 to 0.83 ) over a stress range of $(10-100 \mathrm{kPa})$. The specimen without stabilization shows an originally over consolidated reaction, with yield is took place at approximately a $50 \mathrm{kPa}$ vertical effective stress as stated by (Butterfield, 1979). Also, for the sample without stabilization, the compression index (Cc) was found to be 0.294. Whereas the stabilized samples have very comparable compression performance, with a void ratio varying relating to the marble content contents over the same stress range. The values of compression index reduced steadily, it was found to be $(0.176,0.126$, and 0.12$)$ at a marble content of $(5,10$, and 15 mass $\%)$ respectively. While, the swelling response of the reinforced sample was partly to thoroughly eliminated because of the formation of harden material (CHS). This composite material acted as a stiff element which increase the shear strength and decrease the compressibility.

For the swelling index $(\mathrm{Cr})$ of the normal sample was established to be (0.07) and its value for stabilized samples piercingly decreased. It recorded (0.001) at higher marble content which confirm the elimination of such effect. It is observed that, the marble content, here, customized the 
microstructure of the soft clay-like nanofiller, changed the surface and produced a new composite material with soft clay gallery. The formation of composites with different marble contents through the entire voids can successfully reduce the inter-assembling voids as confirmed by Figure 2c. The initial and final voids ratio together sharply decreased with the increase of the induced material of marble dust. The percentage reduction in the initial voids ratio reached $47 \%$ of its initial rate at a marble content of $15 \%$.

In addition, the effects of the induced composite material on the consolidation settlement of the soft clay were determined as a function of marble content (Figure 2d). The consolidation settlement of unreinforced soft clay sample was recorded through the consolidation tests. It can be experiential that at a constant confining stress, increasing the marble contents from (5\% to $10 \%$ ) resulted in reducing the compression of soft clay of the tested samples. The reduction on the settlement are found to be (45\% and 952\%) was mentioned for both the lower and upper limit of marble content 5 and $10 \%$. It can be noticed that the addition of marble dust as an inclusion resulted in reducing the consolidation settlements.
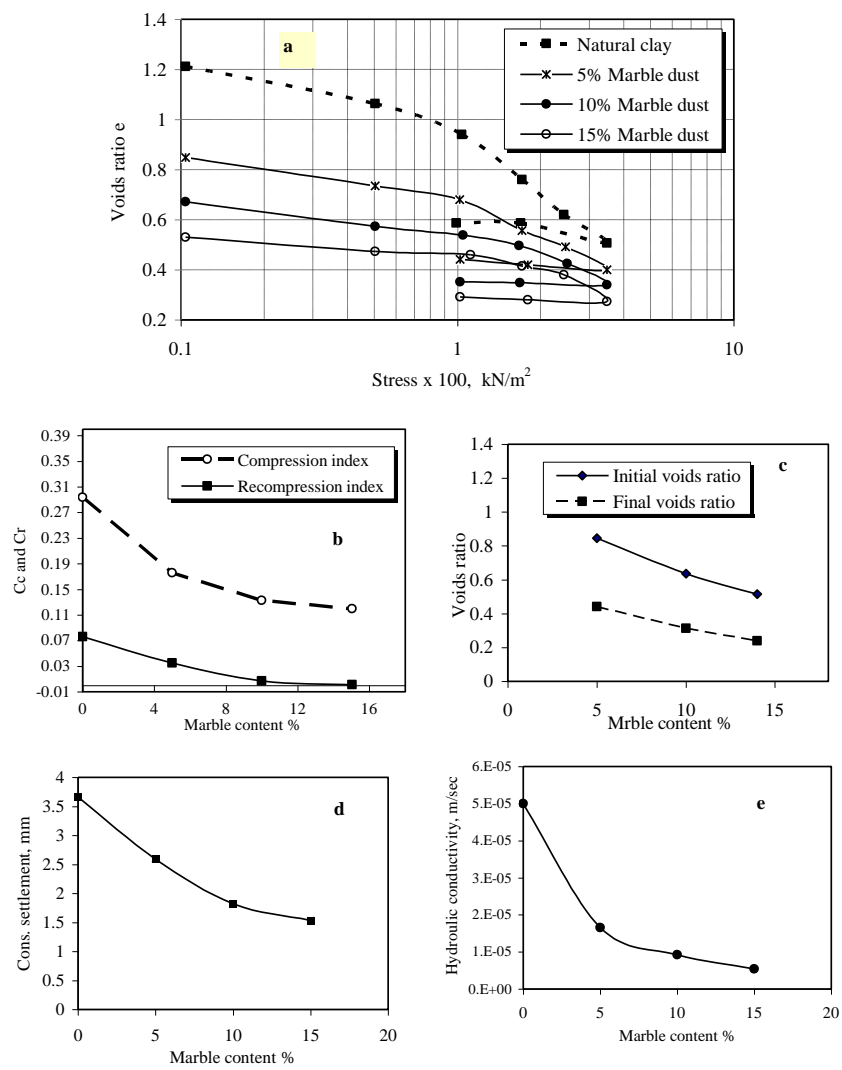

Figure 2: Compressibility behaviors of stabilized soft clay samples by marble dust.

a, (e- $\log$ p) curves for soft clay samples at different marble dust contents $\mathrm{B}$,Variation of marble dust content with compression and swelling index.

c, Variation of marble dust content with initial and final voids ratio.

$\mathrm{d}$, Variation of consolidation settlement with of marble dust content.

e, Variation of the hydraulic conductivity with of marble dust content.
On the other hand, the coefficient of permeability was considered for the reinforced sample at different marble content contents, based on the compressibility relations. It is found that the variation of soft clay by inducing composite material noticeably reduced the permeability of the treated sample (Figure 2e). This also again confirms the efficiency of such stabilized technique that reduces the internal voids and again confirms the discussion that reported the induced composite material. As the marble dust contents increase, the hydraulic conductivities stridently decrease, as clearly plotted in Figure 2e. The obtaining minimum and maximum hydraulic permeability were found to be $5.4 \times 10^{-6} \mathrm{~m} / \mathrm{s}$ for treated clay and $5 \times 10-5 \mathrm{~m} / \mathrm{s}$ for soft clay without additives. It can be finished that the development of composite material nearly packed the entire voids in the normal soft clay sample at a marble content of $15 \%$.

\section{EFFECT OF MARble Dust on The Volumetric CHANGES}

The variations in staring resulting from the volumetric shrinkage with marble content are plotted in Fig. 3. It can be seen that the addition of marble content to form composite materials significantly reduced the volumetric shrinkage of the treated tested soft clay. In general, the use of such marble dust for the reinforcing process shows relatively isotropic behaviour with respect to both the diametrical and axial shrinkages because there is a trivial difference around $5-7 \%$ in the recorded values, as clearly shown in the relevant Figure 3 .

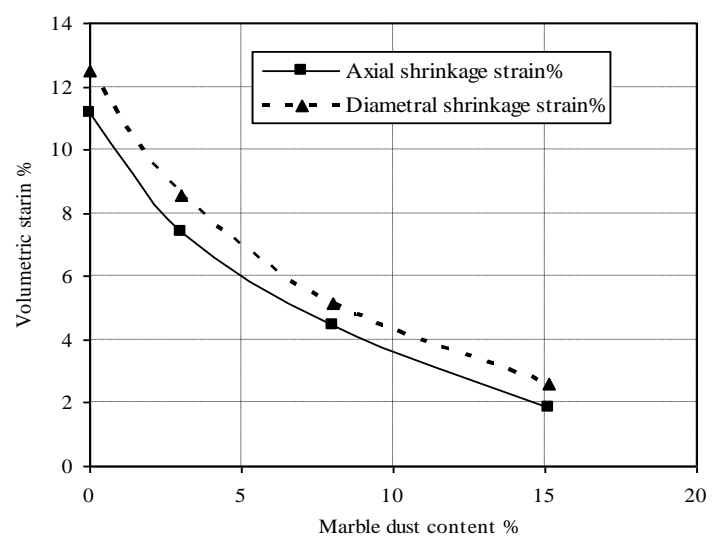

Figure 3: The axial diametric shrinkage strain with marble dust content.

\section{EFFeCt of MARble Dust on The Soft Clay COHESION}

The effect of marble content and induced composites material on unconfined compression behaviour of tested samples (stress-strain) is shown in Fig. 4. It is experiential that, the addition of marble dust led to a considerable increase in the peak axial stress, even though the corresponding strain to peak vertical stress decreased faintly. The increase of shear strength and obtained cohesion once 
more confirmed the formation of composite harden material through the mix. This evidently increased the adhesion between soft clay particles resulting in a homogenous isotropic composite material. Consequently, the reinforced soft clay exhibited more plastic response compared with soft clay without reinforcement. Normal samples disintegrated and ideal shear failure exhibited in its plane in the form of brittle failure (distinct shear plane). Even as the existence of such marble dust with the soft clay modified the shear failure to plastic one in the form of bulging failure. This also established that the clay-marble content produced an isotropic and stiff ductile material. It was noticed that no peak failures were obtained because the produced material increased the stiffness and ductility of stabilized clay.

The improvement degree in the unconfined compressive strength with marble content is clearly observed. Increasing the marble content increased the unconfined compression strength of the soft clay in an approximate linear relationship. The improvement is reached (7 and 5 times of normal soft clay for marble content of (10\% and 15 mass \%) respectively. This mentioned that the achieving composite new material with the soft clay particles had an extensive result on increasing the shear strength with lesser vertical deformation as shown in Figure 4.

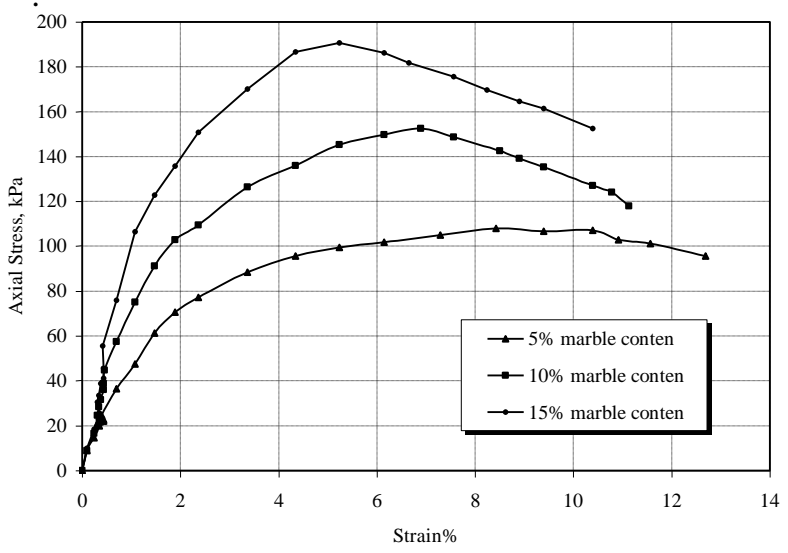

Figure 4: Stress-strainbehaviour of soft clay samples at different marble content.

\section{CONCLUSION}

From the laboratory results of the study, the application of using waste available material in the form of marble dust in improving the geotechnical behaviour of soft clay is presented. It is appreciably improved the soft clay response and preventing the foundation from disaster and controlling the settlement. The following conclusions can be summarized:

1. Stabilizing the soft clay soils with marble dust is a good selection to create a composite hardens material and modifies the clay behaviour.
2. The induction of reinforced composite material successfully decreases and adsorbs the excess water inside the soft clay thus, modifying the soft clay plasticity.

3. The addition of such marble dust can significantly increase the soft clay stiffness and decrease the compression index.

4. The marble dust has an immense effect on decreasing the entire voids and increasing the effective yield stress and decreasing the compressibility behaviour of the reinforced soft clay samples.

5. The used marble dust reducing the volumetric shrinkage and produced isotropic compressible ductile material with less settlement and higher shear strength.

6. This adopted method will be applied to unravel the geotechnical stabilization issues, for instance, road embankments modification and foundation uses.

\section{REFERENCES}

[1] Theng, B.K.G., 1982. Clay-marble content interactions. Summary and perspectives. Clay and Clay Minerals, 30, 1-10.

[2] Dermatas, D and Meng, X.G., 2003. Utilization of fly ash for stabilization /solidification of heavy metal contaminated soils. J. Eng. Geology, 70, 377-394.

[3] Lahalih, S.M., Ahmed, N., 1998. Effect of new stabilizers on the compressive strength of dune sand. Construction and building Materials, 12, 321-328.

[4] Indraratna, B., 1996. Utilization of lime, slag and fly ash for improvement of a clluvial soil in New South Wales, Australia. Geotech. and Geo. Eng., 14(3), 169-191.

[5] Puppala, A. J. and Musenda, C., 2000. Effects of fibers reinforcement on strength and volume change behavior of expansive soils. Transportation Research Board, Washington D.C., (1736), 134-140.

[6] Green,V, S., Stott, D, e., Norton, L. d., Graveel, J. G., 2000. polyacrylamide olecular weight and charge effects on infiltration under simulated rainfall. Soil Sci. Am. J., 64, 1786-1791.

[7] Daniels, J .L., Inyang, H.I. and Iskandar, I.K., 2003. Durability of Boston blue clay in waste containment applications. J. of Material and Civil Eng.15, 144-155.

[8] Daniels, J.L., Inyang, H.L., 2004. Contaminant barrier material textural response to interaction with aqueous marble contents. J. of Material and Civil .Eng.16, 265-275.

[9] Azzam, W. R., 2012. Reduction of shrinkage welling potential with nanocomposites stabilization. J. of Applied Marble content Science, 123, 299-306.

[10] Hebhoub H, Aoun H, Belachia M, Houari H, Ghorbel E (2011) Use of waste marble aggregates in concrete. Constr Build Mater 25(3):11671171

[11] Okagbue CO, Onyeobi TUS (1999) Potential of marble dust to stabilise red tropical soils for road construction. Eng Geol 53(3-4):371-380

[12] Bharti Jy P, Khan W, Kumar P, Gupta KD (2017) Combined effect of addition of marble dust and fly ash on expansive soil. J Mater Civil Eng

[13] Brooks R, Adeoye FF, Takkalapelli KV (2010) Geotechnical properties of problem soils stabilized with fly ash and limestone dust in Philadelphia. J Mater Civ Eng 23(5):711-716

[14] Ali, K., Shahu, J.T. and Sharma, K.G. (2011): "An experimental study of stone columns in soft soils", Proceedings of Indian Geotechnical Conference, Kochi, India

[15] Saygili A (2015) Use of waste marble dust for stabilization of clayey soil. Mater Sci 21(4):601-606

[16] Sabat AK (2012) A study on some geotechnical properties of lime stabilised expansive soil-quarry dust mixes. Int J Emerg Trends Eng Dev 1(2):42-49 
[17] Li LG, Huang ZH, Tan YP, Kwan AKH, Chen HY (2019) Recycling of marble dust as paste replacement for improving strength, microstructure and eco-friendliness of mortar. J Clean Prod 210:55-65

[18] Babu S, Mary S (2017) Soil stabilization using marble dust. Int J Civil Eng Technol (IJCIET) 8(4):1706-1713

[19] Wardani. S.P.R and Muntohar. A. S., (2011), "Laboratory model test on of improved soil using lime-column", The 3rd \& 5th International Conference Geotechnical Engineering For Disaster Mitigation And Rehabilitation And Highway Engineering, Semarang, Indonesia, 2011, Pp. 271:275. 